Jurnal Pemberdayaan: Publikasi Hasil Pengabdian kepada Masyarakat

Vol. 2, No. 3, Desember 2018, Hal. 421-424

ISSN: 2088 4559; e-ISSN: XXXX-XXXX

DOI:

\title{
PENDAMPINGAN PROGRAM BANK SAMPAH DI PRAWIRODIRJAN, YOGYAKARTA
}

\author{
Iis Wahyuningsih ${ }^{1}$, Ima Dinny Rahmawati ${ }^{2}$ \\ Universitas Ahmad Dahlan, Yogyakarta ${ }^{1,2}$ \\ Email : $\underline{\text { iis.wahyuningsih@pharm.uad.ac.id }{ }^{1}}$
}

\begin{abstract}
ABSTRAK
Salah satu permasalahan yang ada di masyarakat sekitar Kampung Prawirodirjan, Kelurahan Prawirodirjan, Kecamatan Gondomanan, Kota Yogyakarta, adalah kurangnya kreatifitas dalam pengolahan sampah. Program Kuliah Kerja Nyata (KKN) Universitas Ahmad Dahlan yang masuk dalam periode KKN Alternatif 59 ini bertujuan memberdayakan masyarakat dalam program bank sampah yang selanjutnya memfokuskan pada intensifikasi pengolahan sampah. Metode yang dilakukan dengan memberdayakan masyarakat melalui sosialisasi dan pelatihan mengenai pentingnya mengolah sampah, praktek langsung dan pendampingan. Program dilaksanakan pada bulan April dan Mei 2018. Dampak dari program ini adalah : 1) masyarakat trampil dalam mengolah sampah organic dan anorganik, 2) masyarakat terampil dalam manajemen bank sampah, 3) masyarakat dapat membuat karya dari barang bekas.
\end{abstract}

Kata kunci : pengolahan, bank sampah, KKN

\begin{abstract}
One of the problems that exist in the surrounding communities of Prawirodirjan, Gondomanan, Yogyakarta, is the lack of creativity in the processing the waste. Real working course of lectures (KKN) University Ahmad Dahlan in the period of Alternative 59 aims to empower communities in the next garbage bank program focuses on processing waste. Methods undertaken by empowering communities through socialization and training on the importance of waste processing are direct practice and mentoring. The program was carried out in April and May 2018. The impact of this program are: 1) the community of skilled in processing organic and inorganic waste, 2) a skilled community bank management in debris, 3) community can make the work of the thrift.
\end{abstract}

Keyword : Processing, waste, KKN

\section{PENDAHULUAN}

Kampung Prawirodirjan, Kelurahan Prawirodirjan, Kecamatan Gondomanan memiliki permasalahan $\mathrm{m}$ engenai kurangnya kreatifitas pengolahan sampah, hal ini tentu mengakibatkan menumpuknya sampah yang masih bisa diolah di lokasi penyimpanan sampah (bank sampah). Sosialisai mengenai pengolahan sampah yang telah masuk ke dalam masyarakat sudah cukup banyak, mulai dari tokoh masyarakat, dari tingkat RT, RW, kelurahan sampai Pemerintah Kota melalui media cetak tentang “Jogja Menuju Bebas 
Sampah”. Namun kesadaran masyarakat untuk meningkatkan keterampilan dan wawasan mengelola sampah masih kurang.

Selain kurangnya kesadaran masyarakat akan pentingnya keterampilan masyarakat, kurangnya tempat penampungan sampah yang layak (berbeda tiap jenisnya) menjadi salah satu penyebab masalah menumpuknya sampah yang masih bisa diolah, sehingga sampah yang masih bisa diolah banyak yang tidak dimanfaatkan sebagai mana mestinya. Kesadaran masyarakat mengenai pentingnya pengolahan sampah harus ditingkatkan mulai dari memilah sampah plastik, kertas dan organik atau non organik lainya, sehingga proses pengolahan di tempat penyimpan sampah (Bank sampah) lebih maksimal dan optimal.

Tujuan program KKN UAD ini adalah menanamkan pentingnya meningkatkan kreatifitas pengolahan sampah plastik, kertas dan non organik lainnya secara berkala dan berkelanjutan kepada warga masyarakat.

\section{METODE}

Program ini dilakukan dengan melibatkan mahasiswa KKN UAD, dosen pembimbing lapangan dan masyarakat Prawirodirjan, pada bulan April-Mei 2018. Ringkasan metode pelaksanaan beserta jam kerja efektif mahasiswa (JKEM) tersaji pada Tabel 1.

Tabel 1. Metode, Kegiatan , JKEM program KKN UAD di Prawirodirjan

\begin{tabular}{|c|c|c|c|}
\hline No & Metode & Kegiatan & JKEM \\
\hline 1 & $\begin{array}{l}\text { Pendidikan } \\
\text { masyarakat }\end{array}$ & $\begin{array}{ll}\text { Menyelenggarakan } & \text { penyuluhan } \\
\text { Program Bank Sampah } & \end{array}$ & $1 \times 2$ jam \\
\hline 2 & Difusi iptek & $\begin{array}{l}\text { Menyelenggarakan } \\
\text { Pengolahan Sampah Organik Dan } \\
\text { Organik }\end{array}$ & $2 \times 2$ jam \\
\hline \multirow[t]{2}{*}{3} & Praktek & Pelatihan Pembuatan Kompos & $1 \times 2$ jam \\
\hline & & $\begin{array}{l}\text { Pelatihan Pembuatan Piguran Dan } \\
\text { Origami Dari Sampah Kertas } \\
\text { Pelatihan Pembuatan Celengan, } \\
\text { Bunga Plastik, Pot Bunga Dari Botol } \\
\text { Bekas }\end{array}$ & $1 \times 2 \mathrm{jam}$ \\
\hline
\end{tabular}




\section{HASIL, PEMBAHASAN DAN DAMPAK}

Salah satu terobosan besar dalam pengeloaan sampah di Indonesia adalah program bank sampah. Melalui program ini, paradigma yang terbentuk dalam pikiran masyarakat bahwa sampah adalah sesuatu yang tidak berguna dan dibuang begitu saja, diubah menjadi sesuatu yang juga memiliki nilai dan harga. Melalui bank sampah, masyarakat bisa menabung sampah, yang kemudian dalam kurun waktu tertentu bisa menghasilkan uang (Novianty, 2013).

Definisi Bank Sampah menurut Peraturan Menteri Lingkungan Hidup RI Nomor 13 Tahun 2012 adalah tempat pemilahan dan pengumpulan sampah yang dapat didaur ulang dan/atau diguna ulang yang memiliki nilai ekonomi. Sedangkan menurut Green and Clean Kota Bandung mendefinisikan bank sampah sebagai upaya memaksimalkan nilai sampah dengan tujuan menciptakan lingkungan yang sehat, bersih,hijau dan asri, mengurangi sampah ke TPA, mengubah perilaku masyarakat, mendidik masyarakat peduli lingkungan dan berorganisasi, meningkatkan kreatifitas, dan memberikan keuntungan bagi penghasil sampah. (Rustanto, 2013).

Dalam rangka meningkatkan kesadaran masyarakat tentang pentingnya hidup sehat dan selalu menjaga kebersihan di Prawirodirjan, diperlukan keinginan, kesadaran dan konsistensi dari setiap keluarga untuk mewujudkan lingkungan yang sehat, bersih dan kreatif melalui kegiatan pengolahan sampah. Kegiatan ini dilakukan agar masyarakat mampu mengolah sampah organik dan non organik dengan optimal dan maksimal serta terhindar dari penumpukan sampah yang menganggu lingkungan. Gambaran salah satu kegiatan yang dilakukan tersaji pada Gambar 1.

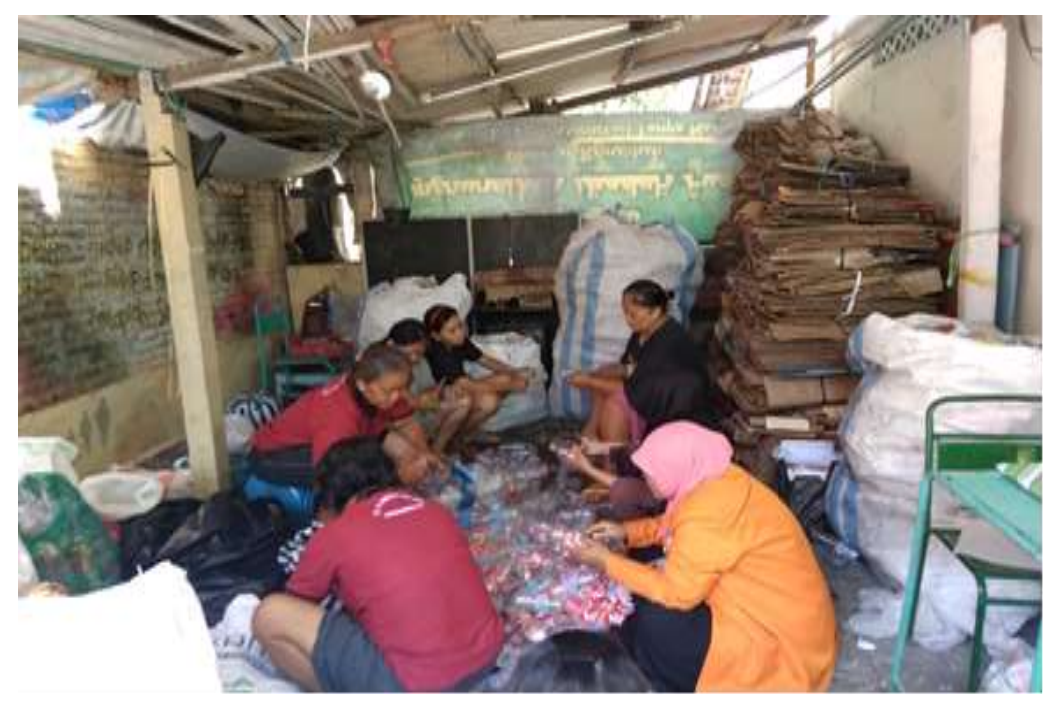

Gambar 1. Pendampingan kegiatan bank sampah 
Dampak yang dapat ditimbulkan dari penumpukan sampah di bank sampah, antara lain:

1. Penyakit

Seperti gangguan pernapasan dan pencernaan akibat polusi udara dari sampah yang menumpuk terutama masyarakat disekitar Bank Sampah.

2. Sampah yang semakin menumpuk karena tidak adanya pengolahan yang optimal dan maksimal. Biasanya permasalahan ini diselesaikan dengan membuangnya sampah yang telah dikumpulkan, sehingga program bank sampah yang sudah ada tidak memiliki manfaat yang maksimal.

3. Sampah yang menumpuk di bank sampah ujung-ujungnya akan dibuang ke TPA sehingga mencemarkan lingkungan. Hal ini tentu menambah tugas pemerintah dan masyarakat sekitar, dan merusak citra penggerak program bank sampah.

4. Sampah yang menumpuk di bank sampah dapat merusak pemandangan.

Keberadaan bank sampah terbukti dapat meningkatkan pendapatan masyarakat di Binjai, Medan walaupun sedikt tetapi memberikan manfaat yang berarti bagi masyarakat. Tidak hanya pendapatan saja yang mengalami peningkatan, tetapi kesehatan, dan interkasi sosial yang lebih baik diantara masyarakat juga yang paling penting adalah lingkungan yang lebih bersih juga mengalami peningkatan dari waktu ke waktu.

Dampak dari program ini adalah : 1) masyarakat trampil dalam mengolah sampah organic dan anorganik, 2) masyarakat terampil dalam manajemen bank sampah, 3) masyarakat dapat membuat karya dari barang bekas.

\section{SIMPULAN}

Tingkat partisipasi masyarakat Prawirodirjan sangat tinggi dalam tahap sosialisasi maupun pelatihan pengelolaan bank sampah.

\section{DAFTAR PUSTAKA}

Novianty, M, 2013, Dampak Program Bank Sampah Terhadap Sosial Ekonomi Masyarakat Di Kelurahan Binjai, Kecamatan Medan Denai, Kota Medan, Skripsi, Fakultas Ilmu Sosial dan Ilmu Politik Departemen Ilmu Kesejahteraan Sosial, Universitas Sumatera Utara.

Rustanto, B. 2013. Bank Sampah. Diakses pukul 14.10 WIB/ 11/ oktober/2018 oleh: http://bambang-rustanto.blogspot.com/2013/08/bank-sampah.html 